\title{
Aplicações e possibilidades terapêuticas do uso do biomaterial quitosana para a Odontologia: revisão da literatura
}

Applications and therapeutic possibilities of the use of chitosan biomaterial for dentistry: literature review Aplicaciones y posibilidades terapéuticas del uso de biomaterial de quitosano para Odontología: revisión de literatura Kelvin Saldanha LOPES ${ }^{1}$

Francisco Willyego Holanda MACIEL ${ }^{1}$

Roque Soares MARTINS NETO²

Vilana Maria Adriano ARAÚJO3

Juscelino de Freitas JARDIM ${ }^{4}$

Mardonio Rodrigues PINTO

${ }^{1}$ Graduação em Odontologia, Centro Universitário Católica de Quixadá - UNICATÓLICA

${ }^{2}$ Residência em Cirurgia e Traumatologia Bucomaxilofacial - Hospital Universitário Presidente Dutra da Universidade Federal do Maranhão (UFMA)

${ }^{3}$ Mestrado em Farmacologia - Universidade Federal do Ceará - UFC

${ }^{4}$ Professor Doutor, Curso de Odontologia, Centro Universitário Católica de Quixadá - UNICATÓLICA

\section{Resumo}

A quitosana, polissacarídeo linear obtido a partir do exoesqueleto de crustáceos e artrópodes, tem sido pesquisada em Odontologia por suas diversas propriedades terapêuticas. O objetivo do presente estudo foi realizar uma revisão da literatura sobre as aplicações atuais e as possibilidades terapêuticas da quitosana na odontologia. A busca foi realizada através do banco de dados eletrônico do Pubmed, utilizando os descritores Quitosana, Odontologia e Biomateriais. Foram incluídas pesquisas científicas utilizando quitosana em diversas áreas da odontologia e excluídas revisões de literatura e estudos não odontológicos, sendo selecionados 13 artigos. A quitosana induz resposta transcricional e anti-inflamatória em fibroblastos gengivais sobre citocinas inflamatórias, fatores transformadores do crescimento (TGF - $\beta$ ) e fatores de crescimento tumoral (TNF- $\alpha$ ) que estão diretamente relacionados à atividade patológica periodontal. Nas infecções endodônticas persistentes, a substância atua criando ligações de hidrogênio e liberação de íons cálcio, o que potencializa a ação dos irrigadores intracanal, além de causar menos estresse oxidativo. Para a odontologia restauradora, a quitosana demonstrou eficácia como auxiliar no condicionamento da dentina e mostrou potencial para induzir a migração de odontoblastos na proteção do complexo dentino-pulpar. A substância atua como uma cura de feridas orais devido à sua capacidade de estimular a formação de fibroblastos e novos vasos sanguíneos, além de células anti-inflamatórias.

Descritores: Biopolímeros; Biomateriais; Biotecnologia.

\section{Abstract}

Chitosan, a linear polysaccharide obtained from the crustacean and arthropod exoskeleton, has been researched in dentistry for its various therapeutic properties. The aim of the present study was to perform a literature review on the present applications and the therapeutic possibilities of chitosan in dentistry. The search was done through the electronic database of Pubmed, using the descriptors Chitosan, Dentistry and Biomaterials. We included scientific research using chitosan in various areas of dentistry, and excluded literature reviews and non-dentistry studies, and 13 articles were selected.. Chitosan induces transcriptional and anti-inflammatory response in gingival fibroblasts on inflammatory cytokines, growth-transforming factors (TGF- $\beta$ ), and tumor growth factors (TNF- $\alpha$ ) that are directly related to periodontal pathological activity. In persistent endodontic infections, the substance acts by creating hydrogen bonds and release of calcium ions, which potentiates the action of intra-canal irrigators, in addition to causing less oxidative stress. For restorative dentistry, chitosan showed efficacy as an aid to dentin conditioning and showed potential to induce odontoblast cell migration in the protection of the dentin-pulp complex. The substance acts as a healing of oral wounds due to its ability to stimulate the formation of fibroblasts and new blood vessels in addition to antiinflammatory cells.

Descriptors: Biopolymers; Biomaterials; Biotechnology.

\section{Resumen}

El quitosano es un polisacárido lineal obtenido del exoesqueleto de crustáceos y artrópodos que se ha investigado en odontología por sus diversas propiedades terapéuticas. El objetivo del presente estudio fue realizar una revisión de la literatura sobre las aplicaciones actuales y las posibilidades terapéuticas del quitosano en odontología. La búsqueda se realizó a través de la base de datos electrónica de Pubmed, utilizando los descriptores Chitosan, Odontología y Biomateriales. Se incluyeron investigaciones científicas que utilizan quitosano en diversas áreas de la odontología, y se excluyeron revisiones de literatura y estudios no odontológicos, y se seleccionaron 13 artículos. El quitosano induce una respuesta transcripcional y antiinflamatoria en fibroblastos gingivales en citocinas inflamatorias, factores de transformación del crecimiento (TGF) - $\beta$ ) y factores de crecimiento tumoral (TNF- $\alpha$ ) que están directamente relacionados con la actividad patológica periodontal. En las infecciones endodónticas persistentes, la sustancia actúa creando enlaces de hidrógeno y liberando iones de calcio, lo que potencia la acción de los irrigadores intracanales, además de causar menos estrés oxidativo. Para la odontología restauradora, el quitosano mostró eficacia como ayuda para el acondicionamiento de la dentina y mostró potencial para inducir la migración de las células de odontoblastos en la protección del complejo dentina-pulpa. La sustancia actúa como una curación de las heridas orales debido a su capacidad para estimular la formación de fibroblastos y nuevos vasos sanguíneos, además de las células antiinflamatorias.

Descriptores: Biopolímeros; Biomateriales; Biotecnología.

\section{INTRODUÇÃO}

A quitosana é um polissacarídeo linear apresentando em sua composição grupos de Dglicosamina e N-acetil-D-glicosamina comumente isolado do exoesqueleto de crustáceos e artrópedes, como caranguejo, camarões e lagostas ${ }^{1}$. Quimicamente, esse biopolímero é muito semelhante à celulose, exceto pelos grupos hidroxila na posição C-2 da celulose que são substituídos pelos grupos amina em quitosana ${ }^{2}$.

A quitosana tem sido relatada como uma substância biocompatível, biodegradável e não tóxica, sendo uma possibilidade terapêutica de ação antifúngica, hemostática, antimicrobiana, analgésica, e na aceleração da cicatrização de feridas. Este polímero já foi explorado para várias aplicações biomédicas, como em andaimes para engenharia de tecidos, na fabricação de fios cirúrgicos, cicatrização óssea e, especialmente, como um material de cicatrização de feridas ${ }^{3}$.

Pesquisas revelam que a quitosana pode atuar 
como excelente cicatrizante em feridas, além de possuir boa capacidade de adesão tecidual ${ }^{4,5}$. Outros trabalhos descrevem o efeito estimulante da quitosana no processo de cicatrização, na formação de tecido de granulação, na angiogênese, na formação de fibras de colágeno e na ativação da resposta imune $^{6}$.

A quitosana tem propriedades interessantes para a produção e desenvolvimento de novos produtos biomédicos, podendo ser usada como membranas bioadesivas, géis, filmes e cápsulas ${ }^{7-9}$. Recentemente, a quitosana demonstrou interesse em estudos para aplicação na área médica $\mathrm{e}$ odontológica. Wieckiewicz et al. ${ }^{10}$ afirmaram que a quitosana pode ser aplicada em vários campos da Odontologia, incluindo a Odontologia restauradora, endodontia, cirurgia, periodontia, prótese dentária e ortodontia $^{10}$.

Para a Odontologia, a literatura mostra que a substância possui propriedades antioxidantes, antibacterianas, anti-inflamatórias, atoxicidade e inibição da formação de biofilme, sendo possível que a substância seja aplicada na produção de colutórios bucais para o controle de placa bacteriana, cimentos dentários, produção de cones endodônticos, onde já existem estudos que realizam testes com essas propriedades. Assim, a versatilidade e biocompatibilidade da quitosana despertam interesse de pesquisadores que visam o desenvolvimento de novos produtos, baseados em suas aplicações tecnológicas e biomédicas visando obter fármacos com mais efetividade e eficácia possibilitando novas opções terapêuticas, o que é de muita significância a Odontologia $^{11}$.

Diante do exposto, o objetivo do presente estudo foi realizar uma revisão de literatura sobre as aplicações presentes e as possibilidades terapêuticas da quitosana para a Odontologia.

\section{MATERIAL E MÉTODO}

Para o presente estudo foram selecionados artigos científicos das bases de dados eletrônicas do Pubmed, dos últimos 2 anos, com os descritores em inglês Chitosan, Dentistry e Biocompatible materials, estando devidamente cadastrados nos descritores em saúde (DeCS). Foram encontrados 438 artigos, dos quais após os critérios de inclusão foram selecionados 13. Para a seleção dos artigos foram lidos os resumos de artigos publicados nos últimos 2 anos, com caráter de pesquisas científicas de testes laboratoriais ou ensaios clínicos e pré-clínicos com o uso da quitosana nas diversas áreas da Odontologia. Foram excluídas revisões de literatura e artigos não relevantes que apresentassem pouco vigor metodológico (Figura 1). Em seguida os dados dos artigos científicos referentes a metodologia e resultado foram contemplados em tabelas, e comparados entre si com base na literatura científica.

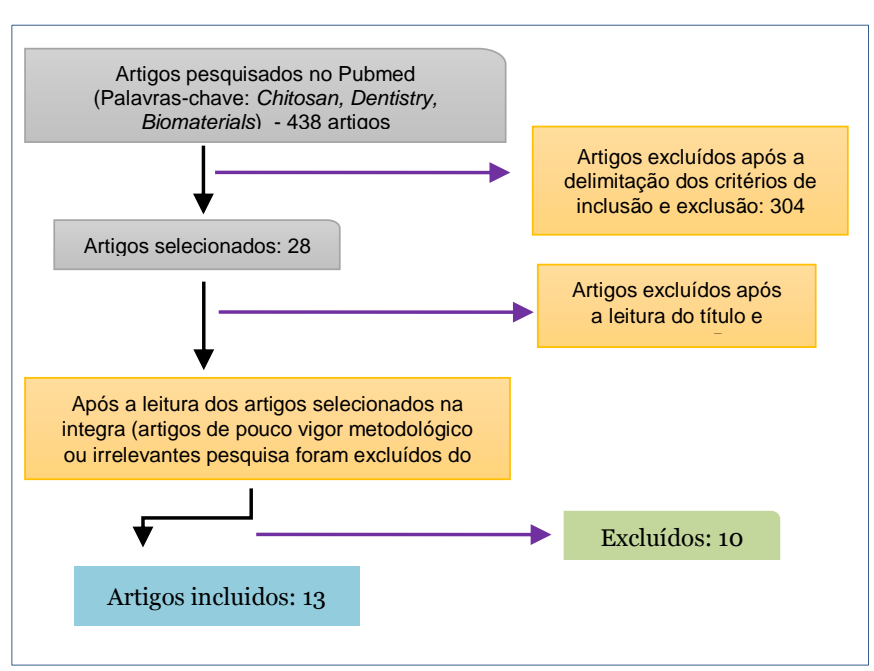

Figura 1: Fluxograma da pesquisa.

\section{RESULTADOS}

As tabelas 1 e 2 apresentam os 13 artigos selecionados quanto ao autor, ano, objetivo e conclusão.

Tabela 1. Artigos selecionados quanto ao autor, ano, objetivo e conclusão

\begin{tabular}{|c|c|}
\hline Autor/Ano & Objetivo \\
\hline $\begin{array}{l}\text { Chen et } \\
\text { al.12, } 2017\end{array}$ & $\begin{array}{l}\text { Investigar o efeito osteocondutor } \\
\text { de arcabouço a base de quitosana } \\
\text { reticulada em um modelo de } \\
\text { defeito craniano em ratos }\end{array}$ \\
\hline $\begin{array}{l}\text { Pavez et } \\
\text { al.13, 2017 }\end{array}$ & $\begin{array}{l}\text { Avaliar os principais genes } \\
\text { regulados pela citocina } \\
\text { inflamatória IL-1 } \beta \text { em culturas } \\
\text { primárias de fibroblastos } \\
\text { gengivais humanos e papel das } \\
\text { partículas de quitosana-triclosan } \\
\text { como agentes antiinflamatórios } \\
\text { capazes de diminuir essa } \\
\text { resposta }\end{array}$ \\
\hline $\begin{array}{l}\text { Moraes et } \\
\text { al. }{ }^{14}, 2017\end{array}$ & $\begin{array}{l}\text { Avaliar a biocompatibilidade e a } \\
\text { osteoindução de uma } \\
\text { biomembrana de quitosana- } \\
\text { colágeno e um arcabouço } \\
\text { contendo cimento de alumínio } \\
\text { de cálcio em calvária de coelhos } \\
\text { comparando ao coágulo e osso } \\
\text { autólogo }\end{array}$ \\
\hline
\end{tabular}

Os arcabouços a base de quitosana reticulada são capazes de estabelecer a formação óssea em defeitos de calota craniana

As partículas de quitosanatriclosan podem ajudar a regular os níveis de inflamação nos tecidos periodontais

A biomembrana e o andaime apresentaram capacidade osteoindutora similar, estimulando o reparo ósseo ao longo dos intervalos de tempo experimentais

A quitosana e o própolis são mais confiáveis em termos de toxicidade que o $\mathrm{NaOCl}$. No entanto, esses resultados por si só não são suficientes para prever o sucesso das soluções de irrigação utilizadas no tratamento endodôntico. Mais estudos in vitro $e$ in vivo são necessários para fornecer uma interpretação mais abrangente da biocompatibilidade dessas soluções

A combinação de atorvastatina com quitosana aumenta o efeit anti-inflamatorio da atorvastatina, bem como a cicatrização óssea e tecidual in vivo em ratos com periodontite induzida

A radiação dos dentes antes do preenchimento do canal radicular foi correlacionada com menor força de adesão, independente da solução final de irrigação utilizada. Além disso, a solução de quitosana aumentou a resistência de união dos dentes submetidos à radioterapia quando comparados aos dentes tratados com NaOCl e EDTA

Essas interações permitiram que nanocarregadores de quitosana / $\begin{array}{lcc}\text { gelatina carreguem e } & \text { e } \\ \text { mantenham a liberação }\end{array}$ mantenham a liberação durante o período experimental et al. 18, gelatina com hidróxido de cálcio Fonte: Dados da pesquisa.

Preparação, otimização
caracterização in vitro de Farhadian nanocarreadores de quitosana / et 18 melhorar seu potencia 
Tabela 2. Artigos selecionados quanto ao autor, ano, objetivo e conclusão

\begin{tabular}{|c|c|c|}
\hline Autor/Ano & Objetivo & Conclusão \\
\hline $\begin{array}{l}\text { Subhi et } \\
\text { al. }{ }^{19}, 2018\end{array}$ & $\begin{array}{l}\text { Avaliar as propriedades físicas e } \\
\text { mecânicas do material de } \\
\text { quitosana à base de gesso e } \\
\text { avaliar seus efeitos nas } \\
\text { propriedades celulares das } \\
\text { células-tronco de dentes } \\
\text { decíduos esfoliados humanos }\end{array}$ & $\begin{array}{l}\text { O material de quitosana a base } \\
\text { de gesso mostra-se promissor } \\
\text { como material potencial para } \\
\text { capeamento pulpar direto }\end{array}$ \\
\hline $\begin{array}{l}\text { Soares et } \\
\text { al. }^{20}, 2018\end{array}$ & 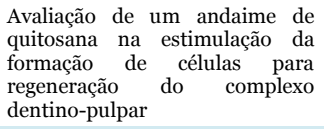 & $\begin{array}{l}\mathrm{O} \text { andaime de quitosana foi } \\
\text { capaz de aumentar a quimiotaxia } \\
\mathrm{e} \text { potencial regenerativo das } \\
\text { células do complexo dentino- } \\
\text { pulpar }\end{array}$ \\
\hline $\begin{array}{l}\text { Özdoğan et } \\
\text { al. }{ }^{21}, 2018\end{array}$ & $\begin{array}{l}\text { Desenvolver um sistema de } \\
\text { entrega bioadesiva para a } \\
\text { entrega local de atorvastatina no } \\
\text { tratamento da doença } \\
\text { periodontal }\end{array}$ & $\begin{array}{l}\text { Os resultados do estudo in vitro } \\
\text { mostrou que a liberação de } \\
\text { citocinas diminuiu com } \\
\text { atorvastatina e a presença de } \\
\text { quitosana aumentou a atividade } \\
\text { anti-inflamatória }\end{array}$ \\
\hline $\begin{array}{l}\text { Kesim et } \\
\text { al. }^{22}, 2019\end{array}$ & $\begin{array}{l}\text { Comparar a eficácia da irrigação } \\
\text { final com quitosana, ácido } \\
\text { etilenodiaminotetracético } \\
\text { (EDTA) e ácido cítrico (CA) em } \\
\text { uma base de resina (AH plus } \\
\text { sealer [Dentsply DeTrey, } \\
\text { Konstanz, Alemanha]) para a } \\
\text { penetração em túbulos } \\
\text { dentinários usando microscopia } \\
\text { confocal de varredura a laser }\end{array}$ & $\begin{array}{l}\text { Quitosana, EDTA e CA } \\
\text { melhoraram significativamente a } \\
\text { porcentagem de selante de } \\
\text { penetração para os terços } \\
\text { coronais }\end{array}$ \\
\hline $\begin{array}{ll}\text { Guo et } \\
\text { al.23 } 2019\end{array}$ & $\begin{array}{l}\text { Avaliar a ação condicionante de } \\
\text { dentina de um material a base de } \\
\text { glicol-quitosana-EDTA solúvel } \\
\text { em água em alto peso molecular }\end{array}$ & $\begin{array}{l}\text { O condicionador de dentina } \\
\text { glicol-quitosana-EDTA solúvel } \\
\text { em água não era citotóxico e } \\
\text { possuía atividades } \\
\text { antibacterianas contra biofilmes } \\
\text { planctônicos e de espécies } \\
\text { únicas, apoiando seu } \\
\text { desenvolvimento contínuo como } \\
\text { condicionador de dentina com } \\
\text { propriedades de secagem ao ar, } \\
\text { anti-proteolíticas as aumentar a } \\
\text { antibacterianas para aumases criadas } \\
\text { durabilidade das ligaçóes } \\
\text { usando a técnica de colagem } \\
\text { etch-and-rinse }\end{array}$ \\
\hline $\begin{array}{l}\text { Susanto et } \\
\text { al. }{ }^{24}, 2019\end{array}$ & $\begin{array}{l}\text { Analisar o efeito da membrana } \\
\text { de quitosana-colágeno na } \\
\text { cicatrização de feridas no defeito } \\
\text { mandibular de ratos, contando o } \\
\text { número de fibroblastos e novos } \\
\text { vasos sanguíneos }\end{array}$ & $\begin{array}{l}\text { A membrana de quitosana- } \\
\text { colágeno foi capaz de aumentar o } \\
\text { número de fibroblastos e novos } \\
\text { vasos sanguíneos no processo de } \\
\text { cicatrização de feridas }\end{array}$ \\
\hline
\end{tabular}

Fonte: Dados da pesquisa

\section{DISCUSSÃO}

Pavez et al. ${ }^{13}$ sintetizaram partículas de quitosana-triclosana e avaliaram sua morfologia, carga, biocompatibilidade e análise de expressão gênica em fibroblastos gengivais humanos. Seus resultados apontaram que a quitosana-triclosan induziu uma resposta transcricional anti-inflamatória nos fibroblastos gengivais de IL-1 $\beta 13$. Sendo confirmado por16, que ao induzir periodontite por ligadura em ratos utilizando grupos de aplicação com atorvastatina $(2 \% \mathrm{p} / \mathrm{v})$ isolada e outro grupo sendo associada a quitosana em gel e um grupo utilizando apenas a quitosana em gel em que após medir os níveis de IL e TGF concluíram que artovastatina associada a quitosana diminuiu os níveis de IL e TGF- $\beta 1$ e a quitosana isolada apresentou variações apresentando cicatrização e diminuição da perda de inserção devido a sua ação anti-inflamatória.

Chen et al. ${ }^{12}$, Özdoğan et al. ${ }^{16}$ e Işılay Özdoğan et al. ${ }^{21}$ aplicaram quitosana em gel e artorvastatina a $2 \%(\mathrm{p} / \mathrm{v})$ em cultura celular com coleta de fibroblastos gengivais humanos induzidas por TNF -alfa, liberação de IL-1 $\beta$, IL-6, IL-8 e TGF$\beta 1$, TGF- $\beta 2$, TGF- $\beta 3$, IL-10 observando que no uso da quitosana em gel a atividade anti-inflamatória aumentava e houve diminuição dos níveis de citocinas nos dois grupos.
Aydin et al. ${ }^{15}$ avaliaram a citotoxicidade e danos oxidativos ao DNA comparando $\mathrm{NaOCl}$, quitosana e própolis como soluções irrigadoras de canais radiculares. As células foram expostas em meio de cultura e os grupos quitosana e própolis apresentaram níveis menores no estresse oxidativo, e resultados estatisticamente próximos em relação a diminuição da viabilidade celular se comparados ao $\mathrm{NaOCl}$. Em seu estudo Farhadian et a. ${ }^{18}$, a partir da síntese de uma solução de quitosana/gelatina, avaliaram a liberação de íons cálcio in vitro em solução tampão fosfato de $\mathrm{pH} 7,4$ por 14 dias, onde foi notada a presença de formação pontes de hidrogênio e algumas interações intermoleculares entre os materiais poliméricos da quitosana/gelatina, devido a capacidade da substância obter uma liberação controlada e prolongada que permitiram carregar o $\mathrm{CH}$ e que mantivessem a liberação sustentada de íons cálcio diminuindo a viabilidade celular e presença de menor estresse oxidativo.

Pajola et al. ${ }^{17}$ estudaram a influência da radioterapia na resistência adesiva a dentina utilizando soluções irrigantes a base de $\mathrm{NaOCl}$, EDTA e quitosana. Os canais foram preparados, subdivididos para irrigação final $(\mathrm{NaOCl}$, EDTA e quitosana). Após isso, três fatias de dentina eram obtidas do terço radicular. Após análise aos testes de ANOVA e Turkey, o grupo $\mathrm{NaOCl}$ obteve menor resistência adesiva, enquanto os grupos EDTA e Quitosana apresentaram maior resistência adesiva.

Corroborando com este estudo Kesim et al. ${ }^{22}$ utilizaram setenta pré-molares mandibulares humanos recém-extraídos para comparar a eficácia de irrigação de canais radiculares nas diferentes regiões dentinárias com os grupos: EDTA $17 \%+2,5 \%$ $\mathrm{NaOCl}$, Ácido cítrico (CA) $10 \%+2,5 \% \mathrm{NaOCl}$, Quitosana $0,2 \%+2,5 \% \mathrm{NaOCl}$ e um controle com $\mathrm{NaOCl} 2,5 \%$. Como resultado obteve boa penetração dos selantes (SP) nos grupos EDTA, CA e quitosana nos terços coronais $(\mathrm{P}<0,05)$ e não houve diferença estatística entre todos os grupos nos terços médio e apical. Quitosana e EDTA mostraram valores médios aumentados de profundidade de SP para os terços médios $(\mathrm{P}<0,05)$ e em todas as secções a profundidade máxima da SP foi significativamente menor no grupo EDTA $(\mathrm{P}<0,05)$.

Em seu estudo, Guo et al.23 utilizaram um condicionador glicol-quitosana-EDTA solúvel em água em alto peso molecular para avaliação do condicionamento dentinário em terceiros molares recém-extraídos e hígidos. As raízes foram removidas e seccionadas paralelamente ao seu longo eixo para remoção de esmalte e dentina superficial, visando garantir que o material teria adesão dentinária compatível ao ácido fosfórico. A aplicação foi feita com ácido fosfórico $32 \%$ por 15 segundos, EDTA por 60 segundos e glicol-quitosana-EDTA em concentrações de 10,25 e $50 \mathrm{mg} / \mathrm{mL}$, por 15,30 e 60 
segundos, seguido de aplicação do Adapter Single Bond 2 (3M ESPE e colagem de resina de $4 \mathrm{~mm}$ de espessura (Z250, 3M ESPE). Como resultado o condicionador de dentina GCE solúvel em água não era citotóxico e possuía atividades antibacterianas contra biofilmes planctônicos e de espécies únicas, apoiando seu desenvolvimento contínuo como condicionador de dentina com propriedades de secagem ao ar, anti-proteolíticas e antibacterianas para aumentar a durabilidade dos laços criados usando a técnica de colagem etch-and-rinse.

Subhi et al. ${ }^{19}$ utilizaram diferentes concentrações de quitosana a base de gesso, com e sem BMP-2, comparadas a grupo controle para realização de capeamento pulpar. Como resultado obteveram que a viabilidade celular para a quitosana a base de gesso foi semelhante ao grupo controle, porém a atividade fosfatase alcalina e propriedades celulares de células-tronco de dentes decíduos esfoliados humanos foi maior e na microscopia de varredura eletrônica foram reveladas células odontoblásticas formadas e distribuídas na superfície do material.

Colaborando com este estudo, Soares et al. ${ }^{20}$ avaliaram o uso de um andaime a base de quitosana em um modelo de câmara pulpar artificial com o objetivo de estimular a formação dentinária no complexo dentino-pulpar, e obteve que o andaime de quitosana propôs a migração de fenótipos odontoblásticos de células pulpares estimulando a fosfatase alcalina, colágeno tipo 1 , fosfoproteína 1 , matriz ácida de dentina sialofosfoproteína dentinária em fenótipos odontoblásticos de células pulpares, fazendo com que a quimiotaxia e o seu potencial regenerativo fossem aumentados

Susanto et al. ${ }^{24}$ analisaram o efeito de uma membrana de quitosana-colágeno na cicatrização de feridas na mandíbula de ratos. Foi observado a alteração do número de fibroblastos e novos vasos sanguíneos, com intervalos de 3, 7, 14 e 21 dias. Obteve então que nos dias 3 e 7 a membrana de quitosana apresentou diferença estatisticamente significante de um aumento no número de fibroblastos $(p=0,001$ e $p=0,001)$ e em 3 dias um aumento do número de vasos sanguíneos $(\mathrm{p}=0,04$; $\mathrm{p}<0,05)$.

Colaborando com esse estudo, Chen et al. ${ }^{12}$ utilizaram scaffolds de quitosana para reparo de defeito ósseo craniano em ratos comparando os resultados com um grupo controle sem intervenção e obteve quantidade de osso regenerado significativamente maior que o grupo controle $(\mathrm{p}$ $<0,05$ ), além de grande atividade anti-inflamatória.

Moraes et al. ${ }^{14}$ estudaram o reparo ósseo em defeitos na calvária de coelhos, em quatro grupos de intervenção: um com biomembrana de quitosana, outro com um scaffolds de aluminato de cálcio, um grupo controle e um com osso autólogo. No entanto diferente do que foi relatado no estudo de Chen et al. $^{12}$, o autor encontrou que a biomembrana de quitosana obteve menor cicatrização óssea entre os grupos. Porém a mesma forneceu maior resposta antiinflamatória com diferença estatisticamente significativa para o osso autólogo $(\mathrm{p}<0,05)$ concordando com o trabalho de Susanto et al. ${ }^{24}$, demonstrando a ação anti-inflamatória da quitosana, propriedade esta que possui aplicação em regeneração tecidual e óssea.

CONCLUSÃO

Com o presente estudo foi visto que a quitosana possui aplicações odontológicas em infecções periodontais, tratamentos endodônticos, auxilia na união de materiais restauradores ao substrato dentário, estimula a formação de células odontoblásticas em tratamentos do complexo dentino-pulpar e ainda tem ação cicatrizante em feridas bucais. Dentro desses achados obtém-se que a quitosana possui boas perspectivas para seu uso como um material odontológico.

\section{REFERENCIAS}

1. Zhao X, Li P, Guo B, Ma PX. Antibacterial and conductive injectable hydrogels based on quaternized chitosan-graft-polyaniline/oxidized dextran for tissue engineering. Acta Biomater. 2015;26:236-48.

2. Tomihata K, Ikada $\mathrm{Y}$. In vitro and in vivo degradation of films of chitin and its deacetylated derivatives. Biomaterials. 1997;18(7):567-75

3. Citgez B, Cengiz AN, Akgun I, Uludag M, Yetkin G, Bahat N, Ozcan O, Polat N, Akcakaya A, Karatepe O. Effects of chitosan on healing and strength of colonic anastomosis in rats. Acta Cir Bras. 2012;27(10):707-12.

4. Azevedo VVC, Chaves SA, Bezerra DC, Lia Fook MV, Costa ACFM. Quitina e Quitosana: aplicações como biomateriais. Rev Eletr Mater Proc. 2007;2(3):27-34.

5. Tavaria FK, Costa EM, Pina-Vaz I, Carvalho MF, Pintado MM. A quitosana como biomaterial odontológico: estado da arte. Rev Bras Eng Bioméd. 2013;29(1):110-20.

6. Ueno H, Nakamura F, Murakami M, Okumura M, Kadosawa T, Fujinag T. Evaluation effects of chitosan for the extracellular matrix production by fibroblasts and the growth factors production by macrophages. Biomaterials. 2001;22(15):2125-30.

7. Shahid F, Abuzaytoun R. Chitin, chitosan, and coproducts: chemistry, production, applications, and health effects. Adv Food Nutr Res. 2005;49(1):93-135.

8. Croisier F, Jerome C. Chitosan-based biomaterials for tissue engineering. Eur Polym J. 2013; 49(1):780-92.

9. Giovino C, Ayensu I, Tetteh J, Boateng JS. An integrated buccal delivery system combining chitosan films impregnated with peptide loaded 
PEG-b-PLA nanoparticles. Colloids Surf B Biointerfaces. 2013;112(1):9-15.

10. Wieckiewicz M, Boening KW, Grychowska N, Paradowska-Stolarz,U. Clinical Application of Chitosan in Dental Specialities. Mini Rev Med Chem. 2017;17(5):401-9.

11. Ravi Kumar MNV. A análise dos pedidos de quitina e quitosana. R React Funct Polym. 2000;46(1):1-27.

12. Chen CK, Chang NJ, Wu YT, Fu E, Shen EC, Feng CW, Wen $\mathrm{ZH}$. Bone Formation Using Cross-Linked Chitosan Scaffolds in Rat Calvarial Defects. Implant Dent. 2018;27(1):15-21

13. Pavez L, Tobar N, Chacon C, Arancibia R, Martinez C, Tapia et al. Chitosan triclosan particles modulate inflammatory signaling in gingival fibroblasts. J Periodontal Res. 2017; 53(2):232-39.

14. Moraes PC, Marques ICS, Basso FG, Rosseto HL, Pires de Sousa FCP, Costa CAS et al. Repair of Bone Defects with Chitosan- Collagen Biomembrane and Scaffold Containing Calcium Aluminate Cement. Braz Dent J. 2017;28(3):287-95.

15. Aydin UZ, Akpinar KE, Hepokur C, Erdönmez D. Assessment of toxicity and oxidative DNA damage of sodium hypochlorite, chitosan and propolis on fibroblast cells. Braz Oral Res. 2018;32(1):1-8.

16. Özdoğan AI, Ilarslan YD, Kösemehmetoğlu K, Acka G, Kutlu HB, Comerdov E et al. In Vivo Evaluation of Chitosan Based Local Delivery Systems for Atorvastatin in Treatment of Periodontitis. Int J Pharm. 2018;25(1):470-76.

17. Paiola FG, Lopes FC, Mazzi-Chaves JF, Pereira $\mathrm{RD}$, Oliveira HF, Queiroz AM et al. How to improve root canal filling in teeth subjected to radiation therapy for câncer. Braz Oral Res. 2018;32(1):1-9.

18. Farhadian N, Godiny M, Moradi S, Hemati Azandaryani A, Shahlaei M. Chitosan/gelatin as a new nano-carrier system for calcium hydroxide delivery in endodontic applications: Development, characterization and process optimization. Mater Sci Eng C Mater Biol Appl. 2018;92:540-46.

19. Subhi H, Reza F, Husein A, Al Shehadat SA, Nurul AA. Gypsum-Based Material for Dental Pulp Capping: Effect of Chitosan and BMP-2 on Physical, Mechanical, and Cellular Properties. Int J Biomater. 2018;2018:3804293.

20. Soares DG, Anovazzi G, Bordini EAF, Zuta UO, Silva Leite MLA, Basso FG, Hebling J, de Souza Costa CA. Biological Analysis of Simvastatinreleasing Chitosan Scaffold as a Cell-free System for Pulp-dentin Regeneration. J Endod. 2018; 44(6):971-76.

21. Işılay Özdoğan A, Akca G, Şenel S. Development and in vitro evaluation of chitosan based system for local delivery of atorvastatin for treatment of periodontitis. Eur J Pharm Sci. 2018;124:208-16.

22. Kesim B, Burak AK, Ustun Y, Delikan E, Gungor A. Effect of chitosan on sealer penetration into the dentinal tubules. Niger $\mathrm{J}$ Clin Pract. 2018;21(10):1284-90.

23. Guo JM, Makvandi P, Wei CC, Chen JH, Xu HK, Breschi L, Pashley DH, Huang C, Niu LN, Tay FR. Polymer conjugation optimizes EDTA as a calcium-chelating agent that exclusively removes extrafibrillar minerals from mineralized collagen. Acta Biomater. 2019;90:424-40.

24. Susanto A, Susanah S, Priosoeryanto BP, Satari MH, Komara I. The effect of the chitosancollagen membrane on wound healing process in rat mandibular defect. J Indian Soc Periodontol. 2019;23(2):113-18.

\section{CONFLITO DE INTERESSES}

Os autores declaram não haver conflitos de interesse.

\section{AUTOR PARA CORRESPONDÊNCIA}

\author{
Mardonio Rodrigues Pinto \\ Curso de Odontologia \\ Centro Universitário Católica de Quixadá - UNICATÓLICA \\ Rua Juvêncio Alves, 660 - Centro \\ 63900-257 Quixadá - CE, Brasil \\ E-mail: mardoniorodrigues@unicatolicaquixada.edu.br
}

Submetido em 21/08/2019

Aceito em 20/04/2020 